\title{
Goodness-of-fit tests for neural population models: the multivariate time-rescaling theorem
}

\author{
Felipe Gerhard ${ }^{1,2^{*}}$, Robert Haslinger ${ }^{3,4}$, Gordon Pipa ${ }^{2,4,5}$ \\ From Nineteenth Annual Computational Neuroscience Meeting: CNS*2010 \\ San Antonio, TX, USA. 24-30 July 2010
}

Statistical models of neural activity are at the core of the field of modern computational neuroscience. The activity of single neurons has been modeled to successfully explain dependencies of neural dynamics to its own spiking history, to external stimuli or other covariates [1]. Recently, there has been a growing interest in modeling spiking activity of a population of simultaneously recorded neurons to study the effects of correlations and functional connectivity on neural information processing (existing models include generalized linear models [2,3] or maximum-entropy approaches [4]). For point-process-based models of single neurons, the timerescaling theorem has proven to be a useful toolbox to assess goodness-of-fit. In its univariate form, the timerescaling theorem states that if the conditional intensity function of a point process is known, then its interspike intervals can be transformed or "rescaled" so that they are independent and exponentially distributed [5]. However, the theorem in its original form lacks sensitivity to detect even strong dependencies between neurons. Here, we present how the theorem can be extended to be applied to neural population models and we provide a step-by-step procedure to perform the statistical tests. We then apply both the univariate and multivariate tests to simplified toy models, but also to more complicated many-neuron models and to neuronal populations recorded in V1 of awake monkey during natural scenes stimulation. We demonstrate that important features of the population activity can only be detected using the multivariate extension of the test.

\section{Conclusions}

The time-rescaling theorem has been used extensively to assess goodness-of-fit and to compare different single-

\footnotetext{
* Correspondence: felipe.gerhard@epfl.ch

'Laboratory of Computational Neuroscience, Brain Mind Institute, Ecole

Polytechnique Federale de Lausanne, 1015 Lausanne, Switzerland
}

neuron models. Multivariate population models became popular only recently. Some of the approaches did not attempt any goodness-of-fit analysis at all or used the time-rescaling theorem separately for each modeled spike train. The proposed multivariate time-rescaling theorem fills the missing gap. Our studies using experimental data show that the use of the univariate theorem may erroneously indicate a good fit for independent encoding models. The lack of fit is detected by the multivariate extension and can be partly corrected for by including additional cross-interaction terms in the model. Overall, the proposed procedure is a simple-toimplement analysis tool for any population model that is based on the conditional intensity formalism.

\section{Acknowledgements}

The authors thank Sergio Neuenschwander and Bruss Lima for supplying the experimental data.

\begin{abstract}
Author details
'Laboratory of Computational Neuroscience, Brain Mind Institute, Ecole Polytechnique Federale de Lausanne, 1015 Lausanne, Switzerland. ${ }^{2}$ Frankfurt Institute for Advanced Studies, 60438 Frankfurt am Main, Germany. ${ }^{3}$ Martinos Center for Biomedical Imaging, Massachusetts General Hospital, Charlestown, MA 02129, USA. "Massachusetts Institute of Technology, Department of Brain and Cognitive Sciences, Cambridge, MA 2139, USA. ${ }^{5}$ Max-Planck Institute for Brain Research, Department Neurophysiology, 60528 Frankfurt am Main, Germany.
\end{abstract}

Published: 20 July 2010

\section{References}

1. Truccolo W, Eden UT, Fellows MR, Donoghue JP, Brown EN: A point process framework for relating neural spiking activity to spiking history, neural ensemble, and extrinsic covariate effects. J Neurophysiol 2005, 93(2):1074-1089.

2. Pillow JW, Shlens J, Paninski L, Sher A, Litke AM, Chichilnisky EJ, Simoncelli EP: Spatio-temporal correlations and visual signaling in a complete neuronal population. Nature 2008, 454(7207):995-999.

3. Truccolo W, Hochberg LR, Donoghue JP: Collective dynamics in human and monkey sensorimotor cortex: predicting single neuron spikes. Nature Neuroscience 2009, 13(1):105-111. 
4. Schneidman E, Berry MJ, Segev R, Bialek W: Weak pairwise correlations imply strongly correlated network states in a neural population. Nature 2006, 440(7087):1007-1012.

5. Brown EN, Barbieri R, Ventura V, Kass RE, Frank LM: The time-rescaling theorem and its application to neural spike train data analysis. Neural Computation 2002, 14(2):325-346.

doi:10.1186/1471-2202-11-S1-P46

Cite this article as: Gerhard et al: Goodness-of-fit tests for neural population models: the multivariate time-rescaling theorem. $B M C$ Neuroscience 2010 11(Suppl 1):P46.

Submit your next manuscript to BioMed Central and take full advantage of:

- Convenient online submission

- Thorough peer review

- No space constraints or color figure charges

- Immediate publication on acceptance

- Inclusion in PubMed, CAS, Scopus and Google Scholar

- Research which is freely available for redistribution

Submit your manuscript at www.biomedcentral.com/submit
C Biomed Central 